\title{
Migration Behaviour of Barium and Strontium in Granite
}

\author{
By S. Hatipoğlu ${ }^{1}$, H. Göktürk ${ }^{1}$ and H. N. Erten ${ }^{2}$ \\ ${ }^{1}$ Department of Chemistry, Middle East Technical University, 06531, Ankara, Turkey \\ ${ }^{2}$ Department of Chemistry, Bilkent University, 06533, Ankara, Turkey
}

\section{Granite / Sorption / Batch method / Column method / Retardation factor / Distribution ratios}

\section{Summary}

The sorption behaviour of $\mathrm{Ba}^{2+}$ and $\mathrm{Sr}^{2+}$ cations on granite have been studied under flowing and static conditions in column and batch experiments. ${ }^{133} \mathrm{Ba},{ }^{90} \mathrm{Sr}$ and ${ }^{3} \mathrm{H}$ were used as radio tracers. The retardation factors, $R_{f}$, and distribution ratios, $R_{d}$, of barium and strontium in column experiments were found to be smaller than those from batch experiments. In both techniques barium was sorbed more strongly on granite than strontium. Sorption energies were found to be in good agreement with literature values.

\section{Introduction}

Geological matrices surrounding a waste repository are expected to act as natural barriers to both water flow and radionuclide migration, since many radionuclides sorb strongly on clays and rocks. Several such sorption studies are reported in the literature [1-14]. Granite, the most common igneous rock which consist of orthoclase, quartz and muscovite appears to be an excellent candidate for a repository area. The general formula of these constituent minerals are as follows [15]:

Orthoclase: $\mathrm{K}\left(\mathrm{AlSi}_{3} \mathrm{O}_{8}\right)$

Quartz: $\mathrm{SiO}_{2}$

Muscovite: $\mathrm{KAl}_{2}\left(\mathrm{AlSi}_{3} \mathrm{O}_{10}\right)(\mathrm{OH})_{8}$

Information about granite's sorption capacity can be obtained via batch and column experiments.

In batch experiments, the distribution ratio, $R_{d}$, which expresses the concentration of the sorbed cation on the solid phase to that in the aqueous phase were calculated from the measured initial and final activities using equations given elsewhere [16].

In column experiments migration of a radionuclide is characterized by a retardation factor, $R_{f}$, which is related to the average radionuclide velocity $\left(V_{f}\right)-$ migration rate - in the matrix with respect to the average water velocity $\left(V_{w}\right)$ in the same medium. The column $R_{d}$ values can be extracted from $R_{f}$ 's using the relation:

$$
R_{f}=1+R_{d} \frac{\mathrm{r}_{s} A_{c} u_{w}}{w}
$$

where,

$r_{s}$ : Density of solid matrix $\left(\mathrm{g} / \mathrm{cm}^{3}\right)$
$A_{c}$ : Cross sectional area of the column $\left(\mathrm{cm}^{2}\right)$

$u_{w}:$ Pore water velocity $(\mathrm{cm} / \mathrm{h})$

$w$ : Volumetric flow rate of water in the column $\left(\mathrm{cm}^{3} / \mathrm{h}\right)$

The results of batch and column experiments lead to information on the type of sorption process, sorption energies and the parameters affecting retardation.

Among the several fission products which are discharged into the environment, ${ }^{90} \mathrm{Sr}\left(t_{1 / 2}=28.8 \mathrm{y}\right)$ is important because of its high fission yield and long halflife. Another product with a high fission yield is ${ }^{140} \mathrm{Ba}$ $\left(t_{1 / 2}=12.8 \mathrm{~d}\right)$, a safety hazard during the first hundred days of its release. Furthermore barium is a homolog of radium, an important radioelement in radioactive waste considerations. Barium studies therefore can be used as an analoque to radium. Presumably, if granite has a high sorption capacity for these radionuclides, then it can be used as a host rock in radioactive waste deposition.

In this work the sorption behaviour of $\mathrm{Ba}^{2+}$ and $\mathrm{Sr}^{2+}$ cations on granite has been studied by employing both batch and column techniques. ${ }^{133} \mathrm{Ba},{ }^{90} \mathrm{Sr}$ and ${ }^{3} \mathrm{H}$ were used as radiotracers.

\section{Experimental}

The column and batch experiments were carried out at room temperature. ${ }^{133} \mathrm{Ba},{ }^{90} \mathrm{Sr}$ and ${ }^{3} \mathrm{H}$ radionuclides which were obtained from the Radiochemical Center, Amersham were used as tracers. The solid matrix granite was obtained from deposits of Central Anatolia. Fourier transform infrared (Fig. 1), X-ray diffraction (Fig. 2) and differential thermal gravimetric analysis studies were carried out to elucidate the structure of granite matrix. Particle size fractionation gave a weighed average particle size of $161 \mu \mathrm{m}$ and surface area measurements indicated $0.75 \mathrm{~m}^{2} / \mathrm{g}$ specific surface area.

All solutions were prepared using synthetic groundwater with a composition similar to the groundwater around the granite deposit. The composition of the synthetic groundwater is given in Table 1 .

In column experiments, retardations of radionuclides were determined by measuring the effluent activities collected from the bottom of a mini-column system which was $0.32 \mathrm{~cm}$ in diameter and $28.7 \mathrm{~cm}$ in height (Fig. 3). The column was packed with a weighed amount of granite powder. After four days of 


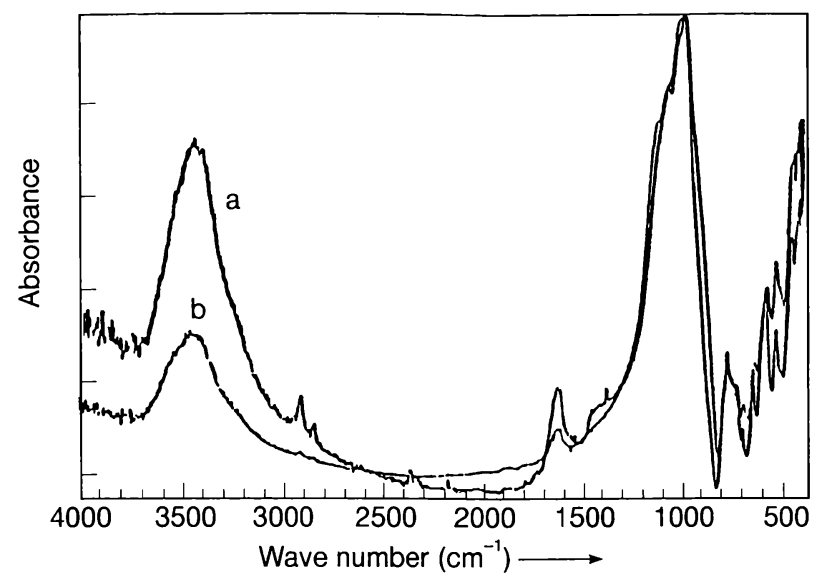

Fig. 1. Fourier transform infrared spectra of: a U.S. Geological Survey Standard Granite, b Granite used in experiments.

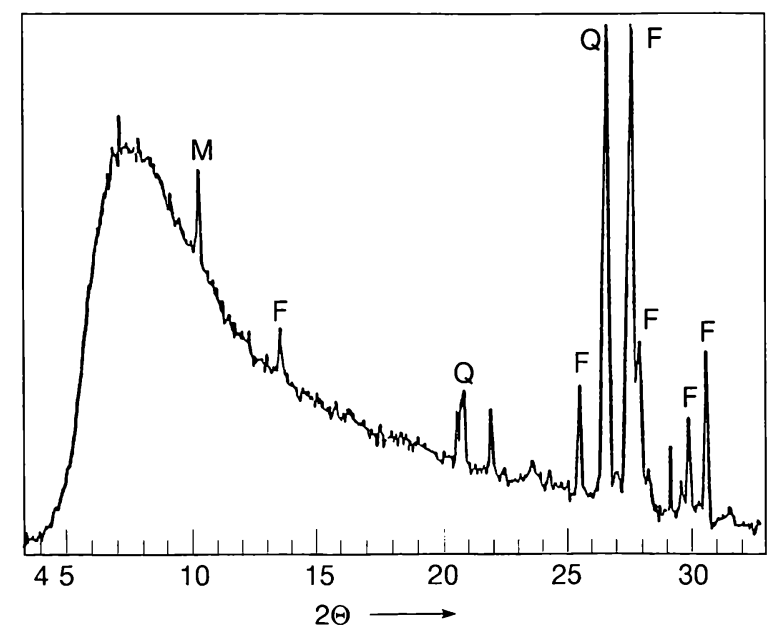

Fig. 2. XRD-traces of granite, (Ni filtered $\mathrm{Cu} K_{a}$ radiation). M: Mica, F: Feldspar, Q: Quartz.

Table 1. Composition of synthetic groundwater used in the sorption experiments

\begin{tabular}{llllllllll}
\hline \multicolumn{9}{c}{ Ion concentration (meq/mL) } & $\mathrm{pH}$ \\
\cline { 1 - 7 } $\mathrm{Na}^{+}$ & $\mathrm{K}^{+}$ & $\mathrm{Ca}^{2+}$ & $\mathrm{Mg}^{2+}$ & $\mathrm{CO}_{3}^{2-}$ & $\mathrm{NO}_{3}^{-}$ & $\mathrm{Cl}^{-}$ & $\mathrm{SO}_{4}^{2-}$ & \\
\hline 0.89 & 0.89 & 4.70 & 3.15 & 0.17 & 3.14 & 0.84 & 0.18 & 7.80 \\
\hline
\end{tabular}

pre-equilibration with groundwater a spike of radionuclide solution was introduced from the top of the column by injection. The migration of the radionuclide of interest through granite matrix was then initiated with a continuous water flow through the column and the fractions of active solutions passing through the column were collected by a fractional collector at specific time intervals. The water flow rate for barium experiments was $2.1 \mathrm{~mL} / \mathrm{h}$ and that of strontium was $3.4 \mathrm{~mL} / \mathrm{h}$. The activities of the solution samples were determined by $\gamma$-ray spectroscopy $\left({ }^{133} \mathrm{Ba}\right)$, by liquid scintillation counting $\left({ }^{3} \mathrm{H}\right)$ or by $\beta$-counting $\left({ }^{90} \mathrm{Sr}\right)$.

The activities of effluents collected at certain time intervals were normalized as the fraction of initial total

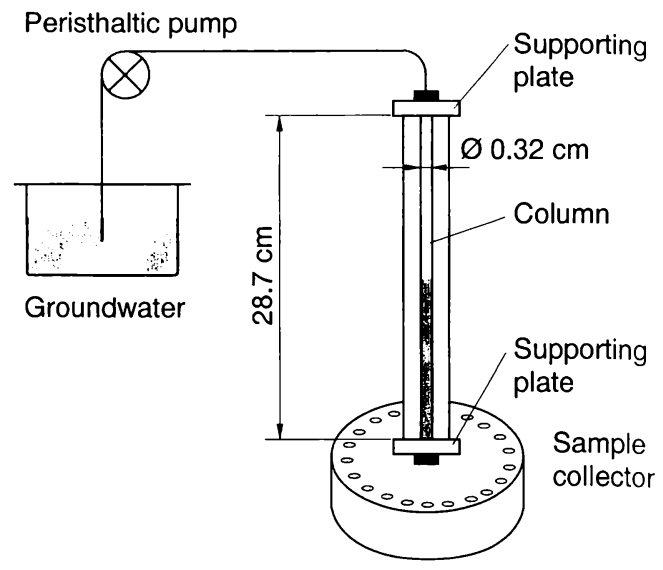

Fig. 3. Mini-column system used in column experiments.

activity. The breakthrough curve of each column experiment was drawn by plotting normalized activities as a function of time. The travelling times of radionuclides obtained from these curves were used to extract the transport velocity of the radionuclide in the granite matrix.

The average water velocity in the same matrix, a necessary parameter in the calculation, was obtained by performing similar column experiments with tritium solutions. Tritium was considered to be a nonabsorbing tracer.

In batch experiments, weighed amount of solid samples were shaken with known volumes of radioactive barium and strontium solutions for certain times. A lateral shaker was used at a rate of $250 \mathrm{rpm}$. Initial cation concentrations before sorption ranged from $10^{-8} \mathrm{~mol} / \mathrm{L}$ to $10^{-2} \mathrm{~mol} / \mathrm{L}$. After separation of the two phases by centrifugation and filtration, the change of adsorbate activity in the aqueous phase was measured and the distribution coefficients were calculated.

\section{Results and discussion}

Typical breakthrough curves obtained in the column experiments of barium-granite and strontium-granite interactions are shown in Fig. 4 and 5 respectively. In Fig. 6 the breaktrough curve of tritiated water is shown. Contrary to the tritium breakthrough curve, tailings were observed to the right of the peaks in barium and strontium curves. This observation is characteristic of chromatographic processes where adsorption is the dominant mechanism leading to retardation.

The velocities of barium, strontium and tritium movements along the column were obtained by dividing the matrix depth with retention times in each column. The retardation factors $\left(R_{f}\right)$ and the distribution ratios $\left(R_{d}\right)$ were calculated accordingly. The results obtained are given in Table 2 .

In batch sorption experiments, kinetic studies indicated that saturation was reached in about fourteendays in both barium-granite and strontium-granite in- 


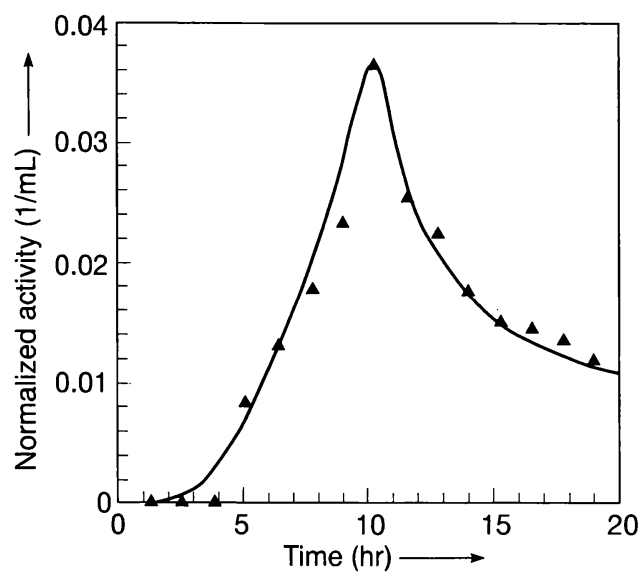

Fig. 4. The breaktrough curve obtained from barium-granite column experiments. Matrix depth: $8.0 \mathrm{~cm}$. $\Delta$ Normalized activity versus time.

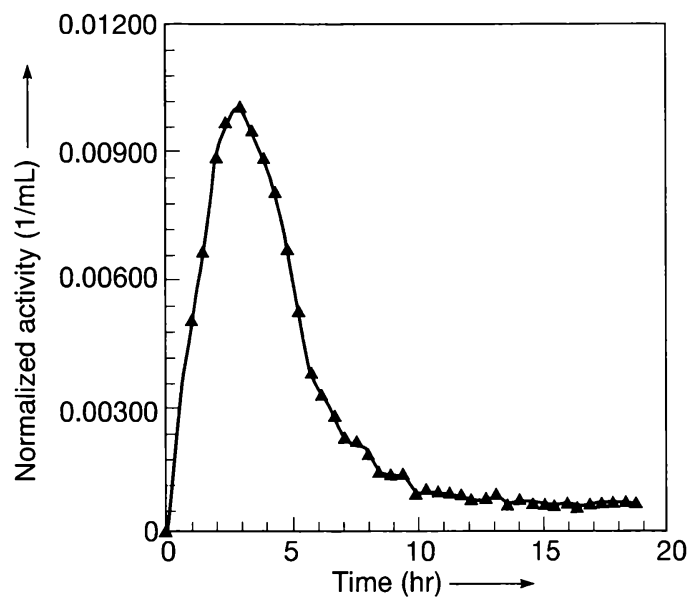

Fig. 5. The breakthrough curve obtained from strontium-granite column experiments. Matrix depth: $5.0 \mathrm{~cm}$. $\Delta$ Normalized activity versus time.

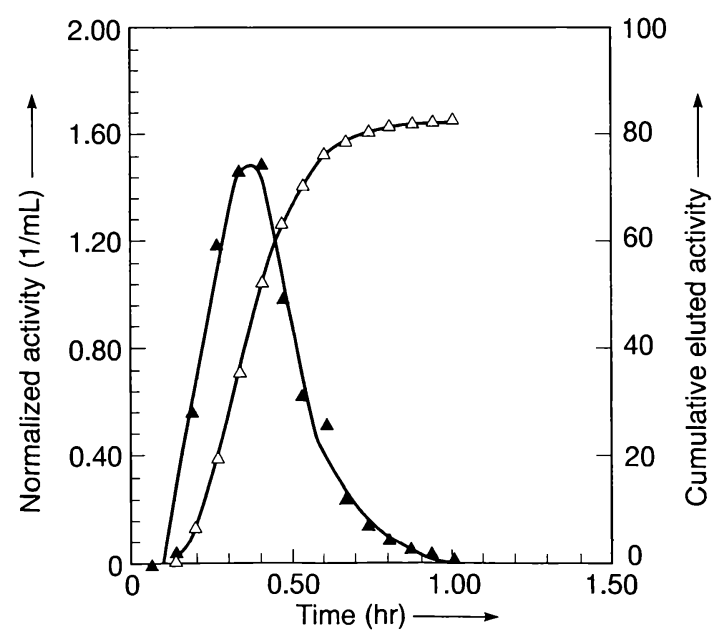

Fig. 6. The breakthrough curve obtained from tritium-granite interactions. Matrix depth: $7.8 \mathrm{~cm}$. $\boldsymbol{\Delta}$ Normalized activity versus time. $\triangle$ Cumulative eluted activity percent versus time.
Table 2. Results of column and Batch experiments for Bagranite $\mathrm{Sr}$-granite interactions

\begin{tabular}{lccc}
\hline Radionuclide & $R_{f}$ & $\begin{array}{c}R_{d}(\mathrm{~mL} / \mathrm{g}) \\
(\text { Column })\end{array}$ & $\begin{array}{c}R_{d}(\mathrm{~mL} / \mathrm{g}) \\
(\text { Batch })\end{array}$ \\
\hline Barium & $37 \pm 3$ & $18 \pm 2$ & $700 \pm 138$ \\
Strontium & $26 \pm 2$ & $12 \pm 1$ & $100 \pm 35$ \\
\hline
\end{tabular}

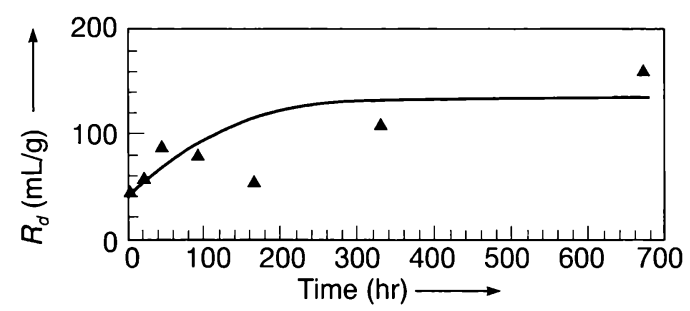

Fig. 7. The time evolution of $\mathrm{Sr}^{2+}$ ion sorption on granite.

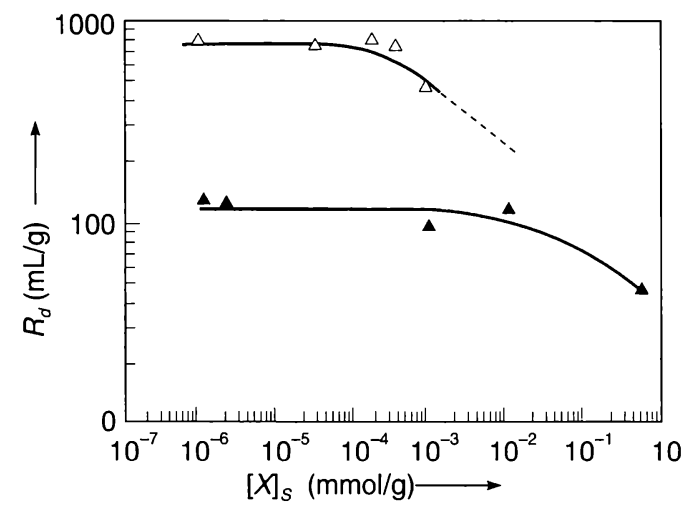

Fig. 8. The change of $R_{d}$ values as a function of cation loadings. $\triangle \mathrm{Ba}^{2+}$ loading. $\Delta \mathrm{Sr}^{2+}$ loading.

teractions. The time evolution of $\mathrm{Sr}^{2+}$ ion sorption on granite is illustrated in Fig. 7.

The variation of the distribution ratios, $R_{d}$, as a function of $\mathrm{Ba}^{2+}$ and $\mathrm{Sr}^{2+}$ ion concentration on the solid phase are shown in Fig. 8. It is seen that the $R_{d}$ values were not strongly dependent on barium loadings in the $10^{-6} \mathrm{mmol} / \mathrm{g}-10^{-4} \mathrm{mmol} / \mathrm{g}$ range. An average saturation $R_{d}$ value of $700 \mathrm{~mL} / \mathrm{g}$ was determined. A sharp decrease in $R_{d}$ values observed above $10^{-4}$ $\mathrm{mmol} / \mathrm{g}$ may be due to the near complete saturation of available adsorption sites. In the case of strontium sorption, $R_{d}$ values were found to vary slightly in the $10^{-6} \mathrm{mmol} / \mathrm{g}-10^{-2} \mathrm{mmol} / \mathrm{g} \mathrm{Sr}^{2+}$ ion loading range. An average $R_{d}$ value of about $100 \mathrm{~mL} / \mathrm{g}$ was determined in this case (Table 2).

The experimental data obtained in the batch experiments were fitted to various sorption isotherm models. They were found to be best described by Freundlich [17] and Dubinin-Radushkevich [18] type isotherms. The isotherm parameters obtained are given in Table 3.

Using these parameters the corresponding empirical Freundlich isotherm for barium-granite sorption system may be expressed as: 
Table 3. Various parameters obtained in fitting of the experimental sorption data to isotherm models

\begin{tabular}{llll}
\hline Isotherm model & Parameter & $\mathrm{Ba}^{2+}$ & $\mathrm{Sr}^{2+}$ \\
\hline Freundlich & $K$ & 285 & 43 \\
& $N$ & 0.95 & 0.94 \\
Dubinin- & $X_{m}(\mathrm{~mol} / \mathrm{g})$ & $1.1 \times 10^{-5}$ & $4.39 \times 10^{-4}$ \\
Radushkevich & $K\left(\mathrm{~mol}^{2} / \mathrm{kJ}^{2}\right)$ & $4.51 \times 10^{-3}$ & $6.26 \times 10^{-3}$ \\
& $E(\mathrm{~kJ} / \mathrm{mol})$ & 10.5 & 8.9 \\
\hline
\end{tabular}

$$
R_{d}=285[\mathrm{Ba}]_{1}^{-0.05} .
$$

Here $[\mathrm{Ba}]_{1}$ is the concentration of $\mathrm{Ba}^{2+}$ in the solution following sorption. The corresponding expression for the strontium-granite sorption becomes

$$
R_{d}=43[\mathrm{Sr}]_{1}^{-0.06} .
$$

In the case of the Dubinmin-Radushkevich type isotherm the empirical relationships can be expressed as

$$
\begin{aligned}
R_{d} & =1.1 \times 10^{-4}[\mathrm{Ba}]_{1}^{-1} \\
& \quad \exp \left[-4.5 \times 10^{-3}\left(R T \ln \left(1+[\mathrm{Ba}]_{1}^{-1}\right)\right)^{2}\right]
\end{aligned}
$$

for barium sorption and

$$
\begin{aligned}
R_{d} & =4.39 \times 10^{-4}[\mathrm{Sr}]_{1}^{-1} \\
& \quad \exp \left[-6.26 \times 10^{-9}\left(R T \ln \left(1+[\mathrm{Sr}]_{1}^{-1}\right)\right)^{2}\right]
\end{aligned}
$$

for strontium sorption.

The sorption energy, $E$, was found as $10.5 \mathrm{~kJ} / \mathrm{mol}$ for barium and $8.9 \mathrm{~kJ} / \mathrm{mol}$ for strontium-granite interaction (Table 3). These are in good agreement with the literature range of $8-16 \mathrm{~kJ} / \mathrm{mol}$ assigned to surface adsorption reactions [19].

To conclude, following observations can be underlined:

Both in the barium-granite and strontium-granite sorption studies the $R_{d}$ values found from batch experiments were much larger than those from the column experiments. Namely $700 \mathrm{~mL} / \mathrm{g}$ and $18 \mathrm{~mL} / \mathrm{g}$ for barium and $100 \mathrm{~mL} / \mathrm{g}$ and $12 \mathrm{~mL} / \mathrm{g}$ for strontium sorptions respectively. This may result from the longer radionuclide-granite interaction times employed in the batch experiments, with the mica fraction in granite being responsible for the observed higher adsorption.

In both cases, the magnitude of the sorption energies suggest that the sorption process is mainly a surface phenomena. A fact which is also supported by the magnitude of isotherm parameters.

Retardation of barium is found to be greater than strontium, which indicates that granite formations are suitable disposal site particularly for radiobarium containing nuclear waste.

\section{Acknowledgements}

Financial support of METU through AFP 88-01-03-02 and AFP 90-01-03-05 are gratefully acknowledged.

\section{References}

1. Vine, E. N., Bayhurts, B. P., Daniels, W. R.: Radionuclide Transport and retardation in Tuff, Los Alamos Scientific Laboratory Report, Los Alamos, NM 87545, 1980, p. 483.

2. Berry, J. A., Bourke, P. T., Coates, H. A., Green, A., Jefferies, N. L., Littleboy, A. K.: Sorption of Radionuclides on Sandstones and Mudstones, Radiochim. Acta 44/45, 135 (1988).

3. Bachhuber, H., Bunzl, K., Schimmack, W. : The Migration of ${ }^{137} \mathrm{Cs}$ and ${ }^{90} \mathrm{Sr}$ in Multilayered Soils: Results from Batch, Column and Fallout Investigations, Nucl. Technol. 59, 291 (1982).

4. Ohnuki, T.: Migration of Radionuclides $\left({ }^{60} \mathrm{Co},{ }^{85} \mathrm{Sr}\right.$ and ${ }^{137} \mathrm{Cs}$ ) in Alkaline Solution ( $\left.\mathrm{pH} 12\right)$ Through Sandy Soil Layer, J. Nucl. Sci. Technol. 23 (7), 71 (1986).

5. Lieser, K. H., Gleitsmann, B., Steinkopff, Th.: Sorption of Trace Elements or Radionuclides in Natural Systems Containing Groundwater and Sediments, Radiochim. Acta 40, 33 (1986).

6. Lieser, K. H., Gleitsmann, B., Peschke, S., Steinkopff, Th.: Colloid Formation and Sorption of Radionuclides in Natural Systems, Radiochim. Acta 40, 39 (1986).

7. Torstenfelt, B.: Migration of the Fission Products Strontium, Technetium, Iodine and Cesium in Clay, Radiochim. Acta 39, 97 (1986).

8. Allard, B., Kipatsi, H., Torstenfelt, B.: Technetium: Reduction and Sorption in Granitic Bedrock, Radiochem. Radioanal. Letters 37, 223, (1979).

9. Konishi, M., Yamamoto, K., Yanagi, T., Okajima, Y.: Sorption Behaviour of Cesium, Strontium, Americium Ions on Clay Materials, J. Nucl. Sci. Technol. 25 (12), 29 (1988).

10. Eylem, C., Erten, H. N., Göktürk, H.: Sorption of Barium on Kaolinite, Montmorillonite and Chlorite, Analyst 114, 351 (1989).

11. Skaqius, K., Svedberg, G., Neretnieks, I.: A Study of Strontium and Cesium Sorption on Granite, Nucl.Technol. 59, 302 (1982).

12. Walton, F. B., Melnyk, T. W., Ross, J. P. M., Skeet, M. M.: Radionuclide Sorption Mechanisms and Rates on Granitic Rock, ACS Symp. Series 246, 45 (1984).

13. Gutierrez, M. G., Bidoglio, G., Avagadro, A., Liano, Y.: Studies on Hydro-Geochemical Controls of Neptunium and Selenium Migration in Granite Columns, Radiochim. Acta 58/59, 277 (1992).

14. Ticknor, K. V., Vandergraaf, T. T., Kamineni, D. C.: Radionuclide Sorption on Mineral and Rock Thin Sections Part II: Sorption on Gratinic Rock, Atomic Energy of Canada Limited Technical Report, TR-385 (1986).

15. Richard, F. F., Skinner, B. J.: Physical Geology, John Wiley and Sons, Inc., London 1928.

16. Erten, H. N., Aksoyoğlu, Ş., Göktürk, H.: Sorption / Desorption of Cs on Clay and Soil Fractions from Various Regions of Turkey, Sci. Tot. Envir. 69, 265 (1988).

17. Freundlich, H.: Colloid and Capillary Chemistry, London, 1926.

18. Dubinin, M. M., Radushkevich, L. V.: Equation of the Characteristic Curve of Activated Charcoal, Proc. Acad. Sci. Phys. Chem. Sec., USSR, 55, 331 (1947).

19. Aksoyoğlu, S..: Sorption of Uranium (IV) on Granite, J. Radioanal. Nucl. Chem., Articles, 134 (2), 393 (1989). 